\title{
How the Asymmetric Information Creates Bubbles in Stock Market?
}

\author{
Haoxian Wang*, Xingyuan Wang, Fan Bu, Guanzhou Wang, Yanqiao Pan \\ Beijing-Dublin International College, Beijing University of Technology, Beijing, China \\ Email: ^1041077884@qq.com
}

How to cite this paper: Wang, H.X., Wang, X.Y., Bu, F., Wang, G.Z. and Pan, Y.Q. (2018) How the Asymmetric Information Creates Bubbles in Stock Market? Open Journal of Social Sciences, 6, 202-215. https://doi.org/10.4236/jss.2018.68016

Received: July 22, 2018

Accepted: August 21, 2018

Published: August 24, 2018

Copyright $\odot 2018$ by authors and Scientific Research Publishing Inc. This work is licensed under the Creative Commons Attribution International License (CC BY 4.0).

http://creativecommons.org/licenses/by/4.0/

(c) (i) Open Access

\begin{abstract}
We analyze the mechanism of creating bubbles under asymmetric information through literature review. Our hypothesis is that information asymmetry will lead to herd behavior and then herd behavior will create bubbles. We find papers and evidences to support our hypothesis. However, after those literature reviews, we consummated our hypothesis and gave a conclusion. Our conclusion is the information asymmetry which can lead to herd behavior and there is a transaction phase. Herd behavior can create bubbles only when shocks come into the market. The bubble will enhance the herd behavior and then further create bubbles. In the first part of our hypothesis, we find three types of papers to support information asymmetry which can lead to herd behavior, which are theoretical model, mathematical model and experiment. It is similar in the second part of our hypothesis, which is herd behavior that can create bubbles.
\end{abstract}

\section{Keywords}

Information Asymmetry, Herd Behavior, Asset Bubbles

\section{Introduction}

The efficient market hypothesis (EMH) illustrates that all the market participants are rational and the price reacts to the information in the market immediately and rationally. According to efficient market hypothesis, all investors are rational and the stock price reflects the information sufficiently and timely. The price is the internal value and the situation like the price deviates from its value does not exist. In other words, there is no bubble in the market. However, in the reality, not all investors are rational and the prices always deviate from the internal value, which means bubbles occurs frequently. Since EMH failed to explain this anomaly, the asymmetric information could be one of the reasons that 
create bubbles. We want to analyze how information asymmetry creates bubbles from the perspective of behavioral finance. There is an important concept called herd behavior. Herd behavior is a kind of behavior that people show conformity when making decisions and judgements. When people are trading in the stock market, we will say they are engaging in herd behavior if they are imitating other investors' trading decisions. Our hypothesis is that information asymmetry leads to herd behavior and then the herd behavior creates bubbles in stock market.

Firstly, we will prove the first part of our hypothesis, which is information asymmetry that can lead to herd behavior. Next, we will prove the second part of our hypothesis, which is herd behavior that can create bubbles in stock market. If these two parts are supported with sufficient evidences, we can say that information asymmetry will create bubbles in stock market by triggering the herd behavior.

\section{Information Asymmetry Can Lead to Herd Behavior}

\subsection{Theoretical Model}

In the study of the existence of bubbles, Allen and Corton $(1991,1993)$ introduced asymmetric information theory into the study of bubbles. Their research shows that the existence of asymmetric information will lead to the bubble in the stock market, and the bubble will come back after it bursts [1].

The efficient-market hypothesis is a theory holds that prices fully reflect all available information. If the stock market is efficient, the stock price will truly reflect the value of the stock. The meaning has two aspects, one is the timeliness, that is, the stock price can quickly reflect all kinds of information. Another is the accuracy, which means the information is true and sufficient.

The establishment of an effective stock market requires several conditions. First of all, the information related to each stock must be disclosed accurately and timely in the market. Secondly, the investor can get the information timely and effectively. Thirdly, the investors must make a consistent and rational judgement of the information. Finally, the investors who make a consistent judgment can take a consistent buying and selling action on the relevant stocks. In these four conditions, the supervisory level and the listed company mainly play a role in the first condition, and the news media mainly play a role in the second condition, and the investors plays a role in the latter two conditions. In fact, these conditions are subject to various constraints when they are executed. Condition 1 reflects the openness of information, which is difficult to achieve. For example, a listed company may exaggerate its advantages and hide its shortcomings for its own sake, so the information may not true and effective. Condition 2 reflects the time difference from information disclosure to information acceptance. Because of the different information acquisition methods, it is impossible to achieve zero time lag, and in the process of information transmission, it will also be affected by news media and other subjects. Condition 3 reflects the effectiveness of investors' judgments on information. Because different investors have different backgrounds and levels of education, their value standards and 
professional ability are also different. This difference will lead them to make different judgments on the same information. Condition 4 reflects the effectiveness of investment decisions. Because investors are subject to various objective conditions in implementing the decision-making process, such as the different trading locations and trading technologies, it will affect the effectiveness of decision-making.

Information plays an important role in stock market and the effects of information are shown in Figure 1. Pre-recipients of good information can raise fund early, while post-recipients enter the market after the rise of stock price. Due to the existence of herd effect, short-termism and different expectations, when more and more investors especially the noise traders join the purchase, a large amount of money will flow into the stock market, so the stocks will be in short supply. Eventually, it leads to the stock market bubble. The following diagram is about the stock market bubble production mechanism based on the perspective of different stockholders.

When the informed traders aware the herd behavior in the market, they will further increase prices and attract more investors to purchase. With more funds pour in the market, the herd effect and behavior of "buying the winners" become more crazy. Therefore, what are the reasons for the existence of herd behavior in the Chinese stock market? The feature of Chinese stock market is that the individual investors are the major participants, account for over $70 \%$ of the total investors [2]. These investors usually lack of professional training, so they are extremely vulnerable to external information and always change their original investment strategy, and they can form the expectations through mutual imitating and learning. This leads to the herd behavior. Nowadays, with the highly developed Internet, the speed of information spreading is greatly accelerated, which further exacerbates the herd behavior of the stock market.

\subsection{Mathematical Model}

\subsubsection{BHW Model}

In the process of deriving the asymmetry of information resulting in herding effects, we have found a classic model and a recent new model.

Bikhchand, Hishleifer, and Welch created the BHW model in 1992. This was

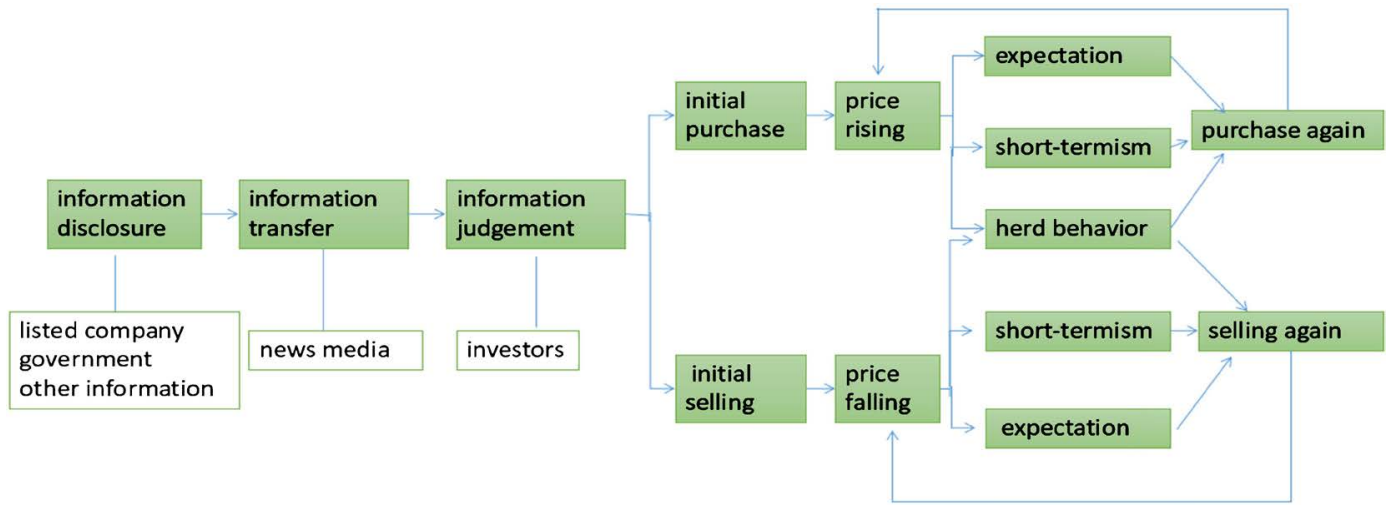

Figure 1. The mechanism of creating bubbles in stock market. 
one of the most famous researches of herding effect, which proved that it was not tough for the market to generate herding effect.

This model assumes that in the situation with uncertain asset values, except public information, investors also have private information, which is related to the value of the asset but incompletely. Since each investor can only observe the actions taken by others without knowing the private information of others, if investors make decisions in a certain order and the investment cost does not change with time, the decision of the forerunner will significantly influence the decision of the latter, which will lead to herding behavior among investors. The experimental assumptions and steps are shown as follows:

Assumptions:

1) All the opportunities in a market are equal to each other.

2) Investors have two options: investing and not investing.

3) Each investor has certain news, and all of them can observe the decisions of other investors before them, but they cannot get news from other investors.

4) Investors are independent, have same initial wealth, and making decisions in order.

5) Suppose there are only two possibilities, which are shown in Table 1, for each investor's return $(S)$ on investment.

6) The random variable $X$ indicates the obtained information, $X=G$ indicates good news, and $X=B$ indicates bad news, and conditional probability:

$$
\begin{gathered}
P(X=G \mid S=1)=p(0.5<p<1), P(X=\mathrm{B} \mid S=1)=1-p \\
P(X=\mathrm{B} \mid S=-1)=p, P(X=G \mid S=-1)=1-p
\end{gathered}
$$

Bayesian formula:

$$
P(S=1 \mid X=G)=\frac{P(X=G \mid S=1) P(S=1)}{P(X=G \mid S=1) P(S=1)+P(X=G \mid S=-1) P(S=-1)}
$$

According to the Bayesian formula, if investor A (the first investor) gets good news, A will invest; if A gets bad news, A will not invest.

Then, $B$ (the second investor) will have four situations. If $B$ observes that $A$ has invested, and B also gets good news, B will invest; if B observes that A does not invest, and B also gets bad news, B will not invest. If B observes that A's investment decision conflicts with his own news, the probability of both B investing and not investing is $50 \%$.

Therefore, the conclusion obtained through the Bayesian formula is that $\mathrm{C}$ (the third investor) observes A (the first investor) and B (the second investor)'s decisions to infer the information they obtain, and then makes decisions based on the information they own and the news they infer. If the first two investors

Table 1. Possibilities for each investor's return on investment.

\begin{tabular}{rcc}
\hline Return $S$ & -1 & 1 \\
Probability & 0.5 & 0.5 \\
\hline
\end{tabular}


have chosen to invest, it can be inferred that the information they have obtained is good, at this time, even if C's news is not good, he will choose to invest. So when the forth investor tries to make decision, he also chooses to invest, so the good news signal for investment starts from C. Similarly, if both A and B do not invest, even if C's news is good, he still chooses not to invest, so the signal of not investing starts from C. So as long as the first two people make the same decision, the third person will give up their own news and follow their decision. Since then the real information chain may be disconnected, so the herd effect starts with the third investor. If the decision made by the first two investors is the opposite, then the third investor will face the same situation as the first investor. He will make decisions based on his own news. Since then, the fourth investor has made the same decision as B (the second investor). Followed by analogy, as long as there are enough investors to make this decision, herding will occur.

\subsubsection{Evolutionary Game Model between Major and Minor Shareholders}

There is a model we find called Evolutionary Game Model between Shareholders generated by a graduated master. As we know, there is a significant difference in the financial strength of shareholders in the securities market, which is divided into major and minor shareholders.

Assuming that: 1) A listed company's stock is quite favored in past and maintains a continuous upward trend. 2) The major shareholders who want to purchase the company's shares have adequate assets, sufficient information, and strong analytical capabilities. 3) Major shareholders can choose depth research or general research. 4) The minor shareholders, who are individual investors in the stock market, cannot afford the cost of collecting and analyzing company information. 5) Minor shareholder will choose whether to follow the choice of the major shareholders by obtaining the news of the major shareholders at a small cost [3] [4].

The major shareholder conducts depth research on the listed company for obtaining information and the cost is $m_{1}$, and the gain obtained is $v_{1}$. The cost of conducting general research is $m_{2}$, and the income obtained is $v_{2}$. The minor shareholder obtains major shareholder's news through various channels and the cost of the news is $c$. When the major shareholder conducts in-depth research and the minor shareholder follows its selection, the minor shareholder's return is $a_{1}$. The major shareholder conducts general researches and the minor shareholder follows its selection. The minor shareholder's return is $a_{2}$. Since the shareholders must be one of three risk types, risk-biased, risk-averse and risk-neutral, minor shareholder's risk preference type is set to $\theta$. When the minority shareholders choose not to follow the major shareholders, the return is the bank's fundamental interest rate, $b$. The strategic exchange table of the major shareholders and minor shareholders is showed in Table 2 [5] [6].

If the proportion of minor shareholders following major shareholders is $x$, then the proportion that does not follow is $1-x$, the proportion of major 
Table 2. The strategic exchange table of the major shareholders and minor shareholders.

\begin{tabular}{|c|c|c|c|}
\hline & & Major Shareholder & \\
\hline \multirow{3}{*}{ Minor Shareholder } & & Depth Research & General Research \\
\hline & Follow & $\left(a_{1}-c\right) \theta, v_{1}-m_{1}+c$ & $a_{2} \theta, v_{2}-m_{2}$ \\
\hline & Not Follow & $b, v_{1}-m_{1}$ & $b, v_{2}-m_{2}$ \\
\hline
\end{tabular}

shareholders who conduct depth research is $y$, then the proportion of conducting general surveys is $1-y . U_{L i}$ and $U_{H i}$ represent minor and major shareholders' returns respectively [6].

$$
\begin{gathered}
U_{L 1}=y\left(a_{1}-c\right) \theta+(1-y) a_{2} \theta \\
U_{L 2}=b y+b(1-y) \\
\overline{U_{L}}=x\left[y\left(a_{1}-c\right) \theta+(1-y) a_{2} \theta\right]+(1-x) b \\
U_{H 1}=x\left(v_{1}-m_{1}+c\right)+(1-x)\left(v_{1}-m_{1}\right) \\
U_{H 2}=x\left(v_{2}-m_{2}\right)+(1-x)\left(v_{2}-m_{2}\right) \\
\overline{U_{H}}=y\left(v_{1}-m_{1}+c x\right)+(1-y)\left(v_{2}-m_{2}\right)
\end{gathered}
$$

After calculating the expectations of the two types of shareholders, establishing a dynamic equation of replication and an equilibrium analysis of the evolutionary game, the conclusion is that by setting $v_{1}-m_{1}>v_{2}-m_{2}$, the optimal strategy for major shareholders is to conduct in-depth research on the company. However, for small shareholders, if they are risk-biased or neutral, then following the decisions of minor shareholders can achieve maximum benefits, which is the typical example of herding effect based on information asymmetry; if they are risk-averse, then the minority shareholders will choose conservative earnings.

Based on this model, it is not difficult for to find that the herding effect caused by information asymmetry is scientifically based and persuasive. We do not deny that many other factors will lead to the emergence of herding, but information asymmetry may be one of the reasons.

\subsubsection{Market Microstructure Model}

Trueman (1996) shows that there is a tendency for analysts to release forecasts closer to those previously announced by other analysis, even when this is not justified by their information. This is a typical representation of herd behavior, it is a phenomenon in which individuals' opinions or behaviors change in the same direction as most people because of the influence or pressure of real or imagined groups. In fact, there is a transition phase exists between the normal phase and the herd phase. During the transition phase, the market liquidity deteriorates, marked by larger bid-ask spread and stronger price impact power. The trades presented in the transition phase have substantial influence on the market price.

We defined that the market is in the transition phase if some informed trad- 
ers' expectation of the asset payoff is within the bid-ask spread, i.e. $\mathrm{B}_{\mathrm{t}}<\mathrm{E}\left(\mathrm{Y} \mid \mathrm{H}_{\mathrm{t}}\right.$, Informed Agent's Signal) $<A_{t}$. Note that $B_{t}$ is the bid price and $A_{t}$ is the ask price. Taking the evolution to herd with consecutive sell orders as an example $\left(\mathrm{w}_{\mathrm{t}}=1 \& \mathrm{v}_{\mathrm{t}}=0\right.$ means informed traders with weak-negative signals).

Figure 2 shows the evolution path from the normal phase to the herd phase. The abscissa is time, which means different trading period, and the ordinate is the stock price. The market maker as an intermediary will buy stocks from investors at price $B_{t}$ and sell stocks to investors at price $A_{t}$, so the fraction will be the profit of market maker. Another line in the figure with the label $\mathrm{E}\left(\mathrm{Y} \mid \mathrm{H}_{\mathrm{t}}, \mathrm{w}_{\mathrm{t}}\right.$ \& $v_{\mathrm{t}}$ ) is the investor's expected stock price. Phase 1 is the normal phase where the informed traders with different signals will act differently. Informed traders with positive signals will buy the stocks while those with negative signals will sell. When the expectation of informed traders with negative signal falls into the bid-ask spread, we enter Phase 2, the transition phase. The informed traders with weak-negative signals will choose not to trade rather than choosing to buy or sell. Phase 3, the herd phase, happens when all the informed traders' expectations concentrate on one side of the price [2].

Furthermore, in the multiple markets, there exists a phenomenon of contagion that the transition phase in one market could affect not only that market but also related markets. If the precision of the informed trader's signal is different in different markets, high precision will make herd behavior unlikely since the informed will more likely follow his signal than follow the trade history. If we mix the high precision and low precision markets together, the herd behavior could be contagious from one market to another.

\subsection{Experiment}

There has been a great many of experiments illustrating the relationship between information asymmetry and herd behavior so far. For instance, Avery and

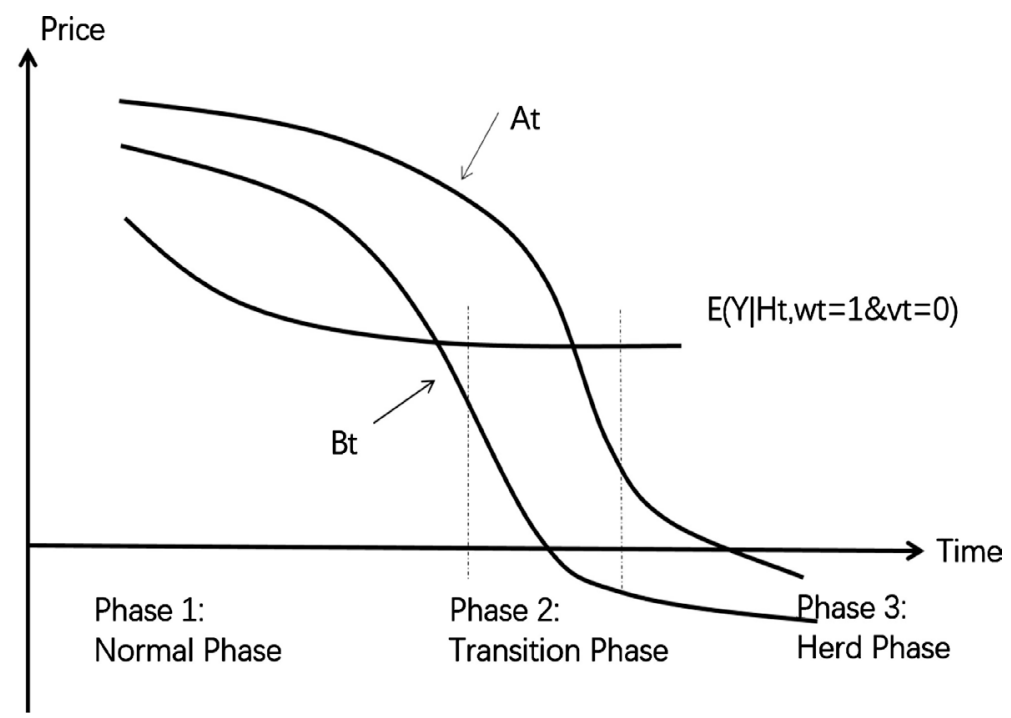

Figure 2. Evolution path from the normal phase to the herd phase. 
Zemsky (1998) displayed that traders never herded in a sequential trading model where the price was directly set by a market maker according to the order flow. Nevertheless, herding emerged if there was uncertainty regarding some characteristics of the market like the proportion of informed traders in the market [7]. Based on it, Cipriani and Guarino (2005) have tested for herd behavior in financial markets using student subjects and they selected financial professionals as subjects in Cipriani and Guarino (2009) [8] [9]. Both experiments utilized similar methods so we will only introduce the latter in more detail in the following.

As a matter of fact, Marco Cipriani and Antonio Guarino explored herd behavior by conducting an experiment in a laboratory financial market at University College London between December 2006 and February 2007. In the process, the 32 participants who were financial professionals working for financial institutions operating in London acted as informed traders and exchanged an asset with a computerized market maker. Besides, the experimenters introduced a new strategy method. To be precise, subjects made conditional orders contingent on any signal realization, instead of choosing an action after observing a realization. With this method, they were capable of eliciting beliefs and detecting herd as well as contrarian behavior directly.

In term of experiment design, the investigators ran two treatments. In Treatment I, all subjects received accurate signals which indicated some events would happen for sure and illustrated that the financial asset price would have an upward or downward trendency. In the meanwhile, the price adjusted to the orders coming from these informed subjects. That means, there was no information asymmetry under this circumstance. By contract, in Treatment II, the investigators implemented the model with uncertainty about the information events and the price adjustment rule was consistent with the presence of event uncertainty. For instance, in an around, $20 \%$ subjects received a signal illustrating that the financial asset price would go up with the probability of $80 \%$ while other subjects were noise traders who did not possess signals. That is to say, there was information asymmetry to some extent in the second treatment. In addition, as for how to identify herd behavior and contrarian behavior in the process, they presented the definition "An informed trader engages in cascade behavior if he chooses the same action independently of the private signal. If the chosen action conforms to the majority of past trades the trader engages in herd behavior. If the chosen action goes against the majority of past trades the trader engages in contrarian behavior". After a range of tests and calculation, the main result statistics were displayed as follows.

As Table 3 and Table 4 show, in the first treatment without event uncertainty, subjects had a tendency to go against the market (contrarian behavior). On the contrary, in the second treatment with event uncertainty, it was apparent that the proportion of herd behavior increased with respect to the first treatment and contrarian behavior disappeared altogether. That is to say, herding will be more likely to occur with the existence of asymmetric information. 
Table 3. Cascade trading behavior in Treatment I.

\begin{tabular}{cccc}
\hline $\begin{array}{c}\text { Absolute value of } \\
\text { the trade imbalance }\end{array}$ & $\begin{array}{c}\text { Cascade } \\
\text { trading (\%) }\end{array}$ & $\begin{array}{c}\text { Herd } \\
\text { behavior (\%) }\end{array}$ & $\begin{array}{c}\text { Contrarian } \\
\text { behavior (\%) }\end{array}$ \\
\hline 0 & 5.8 & & \\
1 & 18.5 & 5.7 & 12.9 \\
2 & 42.7 & 16.1 & 26.6 \\
3 & 54.3 & 23.9 & 30.4 \\
$\geq 4$ & 62.5 & 21.9 & 40.6 \\
\hline
\end{tabular}

Table 4. Cascade trading behavior in Treatment II.

\begin{tabular}{cccc}
\hline $\begin{array}{c}\text { Absolute value of } \\
\text { the trade imbalance }\end{array}$ & $\begin{array}{c}\text { Cascade } \\
\text { trading (\%) }\end{array}$ & $\begin{array}{c}\text { Herd } \\
\text { behavior (\%) }\end{array}$ & $\begin{array}{c}\text { Contrarian } \\
\text { behavior (\%) }\end{array}$ \\
\hline 0 & 2.2 & & \\
1 & 8.2 & 4.4 & 3.8 \\
2 & 23.0 & 18.4 & 4.6 \\
3 & 34.3 & 30.3 & 4.0 \\
$\geq 4$ & 40.4 & 40.4 & 0.0 \\
\hline
\end{tabular}

\section{Herd Behavior Can Create Bubbles in Stock Market}

In behavioral finance, we consider investors are not perfect rational and their investment behavior will be influenced by their emotions and cognitive. These influences will cause individual investment bias and group investment bias, which can lead to herd behavior. These investment biases will push the asset price away from its fundamental value. Under the feedback mechanism, the impact of good news and bad news on asset prices will be magnified continuously which will eventually create bubbles or crash. Herd behavior is a kind of action that imitating other people's action or behavior, which will cause the contagion of investor's opinions or information.

\subsection{Theory}

Robert J. Shiller (2000) gives information about the impact of herd behavior on stock market bubbles in his book called "Irrational exuberance". He illustrates that herd behavior has significant magnification effect on stock market bubbles. Investors' rational mind and rules that they set for themselves in order to be rational will collapse when facing the prospect of an extremely wealthy future [10]. From the moment of disintegration of their rational defense, they stop analyzing the operating and management of the company, the profitability of the company and whether the price departures from its true value. As soon as they know other investors buy, they will blindly believe the price is going up and make a large buy order. Once the price falls, they blindly believe the price will keep falling and sell with other investors. In 2006, Shiller explains the intense fluctuation in US stock market in 1987 from the perspective of investors' behaviors. The increase in in- 
vestors' investment confidence and the continuous rising in price will form the optimistic market sentiment. This kind of sentiment will trigger the herd behavior and further creates bubbles [10].

\subsection{Mathematic Model}

\subsubsection{Dynamic Mathematical Model}

Lux (1995) built a model, which considers the factor of contagion of investors' opinion and actions in his paper "Herd behavior, Bubbles and Crashes". He pointed out that if individual imitating others' behavior will result in a collective herd behavior which further forms the bubbles and crashes [11]. If the market sentiment is optimistic, the existence of herd behavior will impel the investors to imitate others' buy action and the stock price will be much higher than its fundamental value. If the market sentiment is pessimistic, herd behavior will gradually squeeze out the bubble and then beat the price far below its fundamental value.

"Multidimensional Uncertainty and Herd Behavior in Financial Markets" written by Christopher Avery and Peter Zemsky (1998) built a mathematical model to illustrate that herd behavior is capable of magnifying the effect of shocks on stock prices and push the price away from the value. With three-dimension of uncertainty, which means price can be influenced by three kinds of factors such as value uncertainty, event uncertainty and composition uncertainty, herd behavior can lead to significant mispricing [6].

Christian Hott (2007) built a dynamic mathematical model to analyze the occurrence of price bubbles only through one factor called herd behavior in his paper "Herding behavior in asset markets". Other factors such as speculative incentives are ignored. The author introduces mood investors in order to create herd behavior and mood investors trade according to the market sentiment [12]. According to Lux (1995), if there are more investors who are willing to buy the asset, i.e. informed traders receive positive signal, the mood of investors will increase. In this model, if a positive signal comes into the market, which implicates the price will go up, the mood of investors will increase. As the decisions of mood investors are positive related with the market sentiment, an increase in market sentiment will lead to more buying orders and the mood of other investors increases again. The enhanced mood will impel other investors to consider their uninformative signals as positive and increase their investment in the market. In next period, all investors can observe that part of them make their decisions according to a positive signal and this will increase the mood further as well as the price. In this positive feedback process, price will keep rising and deviates from its fundamental value. The author then insert numbers in his dynamic model to deduce the price and at each time under the few constraints, definitions and assumptions made by him. The result shows that herd behavior eventually create a bubble.

\subsubsection{Non-Linear Dynamic Model}

Researchers of herding effect have given different conclusions of whether the 
herding effect will increase stock prices volatility. Some believes that herding effect will lead to a higher price volatility, there are two general direction of such researchers: theoretical models and experimental tests. Researchers either introduced their own model to investigate managers based on reputation such as funds managers, which assumed that the action of a manager that ignore their private signal to follow others will increase the price volatility. Or they quantified the herding effect and interactions between investors to formulate a dynamic market model that illustrate the market investing attitude and stock price volatility.

Others on the contrary, claim that the existence of herding effect will somehow accelerate the convergence of stock price, which will undoubtedly facilitate a market equilibrium. Lakonishok argued that because most of the market was occupied by institutional investors, their sense of ration will simply neutralize those irrational markups made by individual investors, therefore establishing market stability. However, considering the situation that Chinese stock market has almost $70 \%$ of individual investors, this theory might not be applied in our case.

The author questioned the efficiency of previous theoretical analysis for the reason that in their models, no one can really distinguish herding effect from actions that have been made after a thorough analysis. Fortunately, with the development of computer science, researchers will now be able to accomplish this target by simulating a stock market and they have accordingly put forward this pattern: "The price volatility firstly rise then fall when herding effect become more sever"; "This paper has specified the market efficiency by examining the speed of stock price to retrieve equilibrium, then it tried to explain the mutual influence between herding effect and price volatility" (Liu xiaodong 2014) [13].

The author has taken the example of Lux's test, which assumes that there is only 1 stock in the market to trade, when the stock price fluctuates, a buyer of the stock will be noted as an optimistic investor, a seller will be noted as a pessimistic investor. The model will continuously compute the sum of optimistic and pessimistic investors as the average investing attitudes. The change of an investing attitude will then represent the excess demand of stock, therefore illustrating the dynamic equation of financial system and price volatility.

A non-linear discrete stability test has managed to quantify the "Middle level herding effect" by establishing a matrix about market equilibrium. During this test, an interval of middle level herding effect was revealed, a herding effect that is below this interval will be considered as a light herding effect and vise versa. The above configuration of herding effect was tested then.

As for the numerical simulation for indicating the connection between level of herding effect and financial system stability, the author introduced " $r$ " as the level and " $P$ " as the prices.

As is shown in Figure 3 [13], there are six situations with different herd level. The first and second picture with $r=0.01$ and 0.02 respectively illustrate that the 


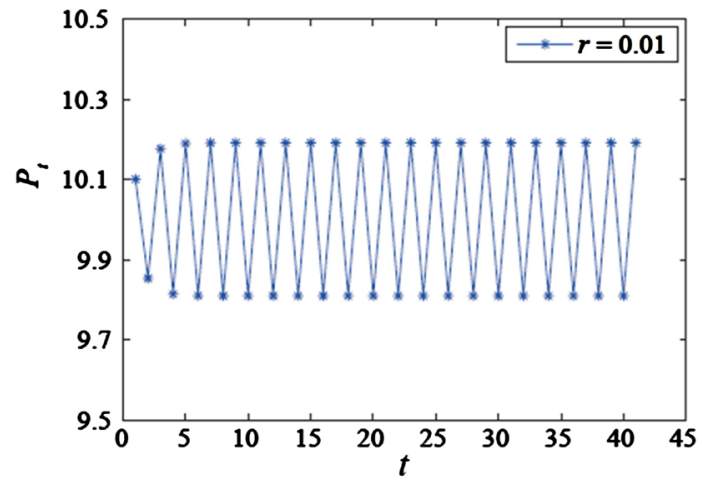

(a)
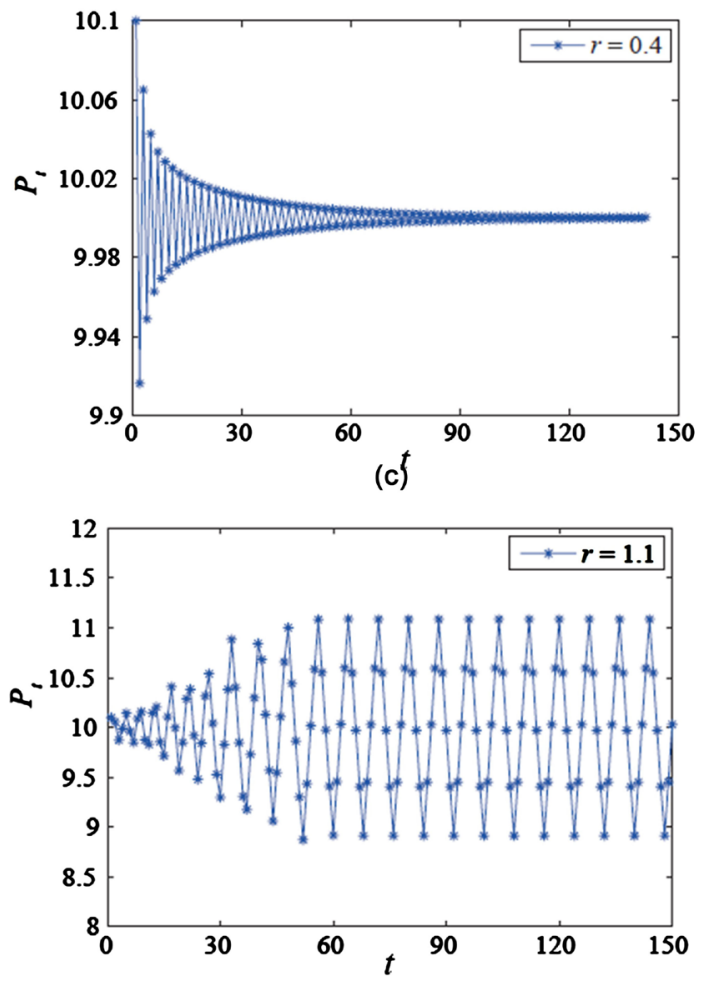

(e)

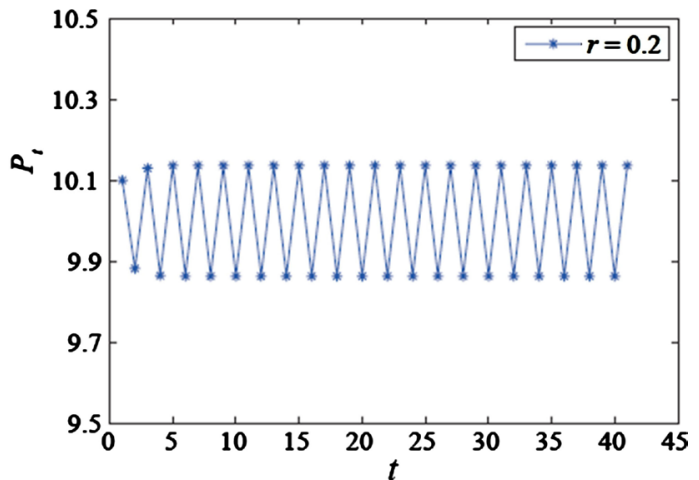

(b)
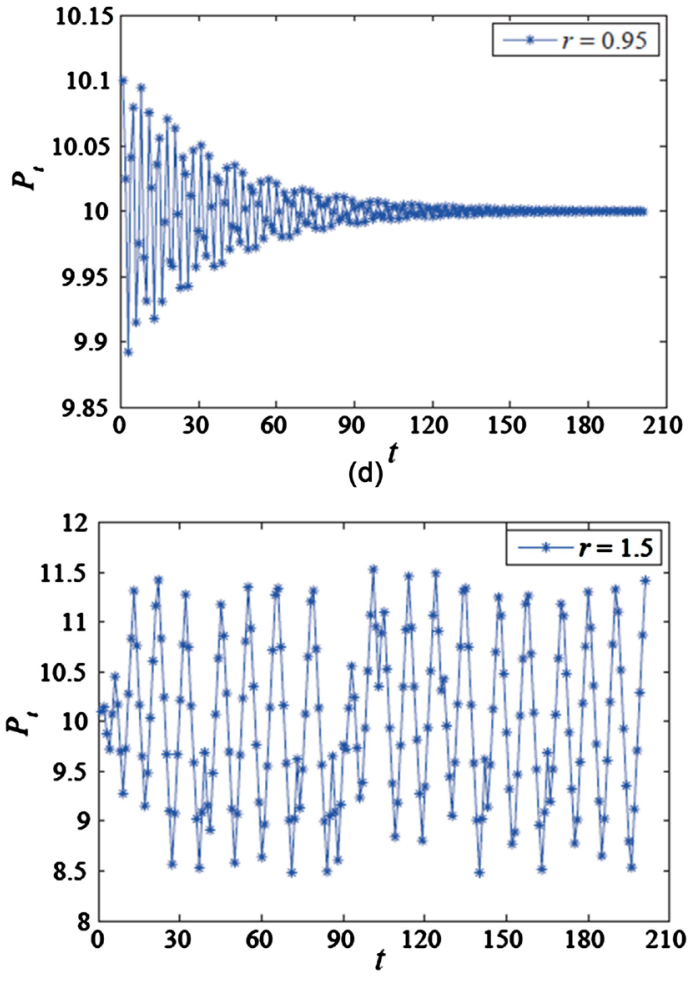

(f)

Figure 3. Price fluctuation under different herd level.

price will have a periodical pattern as time goes by. The third and fourth picture with $r=0.4$ and $r=0.95$ respectively tell us that the price will converge to a specific price through time. The fifth and sixth picture with $r=1.1$ and $r=1.5$ respectively show that the prices are unstable through time.

As it is illustrated, when $r$ is low, the price volatility tends to be periodical stable, when $r$ is in the middle level like 0.4 or 0.95 , the prices of stock ultimately converge. When $r$ is considerably high like 1.1 or 1.5 , the prices of stock became extremely unstable, which in our case, causing price bubbles.

In summary, this paper has taken some example of other's test and established a stock market model, therefore enabled itself to introduce a non-linear dynamic model to specify an interval of middle level herding effect as the financial system can be most likely stable during this interval. It then identified other two levels 
above and beneath it. At the very last of the paper, it revealed the connection between " $r$ " and financial stability, it has successfully led us to the conclusion that a higher herding effect will lead to price bubbles.

\subsection{Summary}

The paper called "An empirical study of herd behavior and stock market bubble", which is written by Li Long, analyzes the relationship between herd behavior and stock market bubbles. Firstly, he used dynamic autoregressive test to examine the bubbles in stock prices in Shenzhen Stock Exchange. The results show that there existed a significant bubble over the span from October 2006 to December 2007. Furthermore, he uses A-CCK method and slide window method to test the herd behavior in Shenzhen stock market. Then he uses linear Granger causality test and nonlinear Granger causality test to illustrate the relationship between herd behavior and stock market bubbles is both linear and non-linear related. When bubbles come into the market, herd behavior will enlarge the bubble and the enlarged bubble will instead enhance the herd behavior [14].

\section{Conclusions}

Overall, we find out that markets with asymmetric information can actually lead to herd behavior. When a shock comes in this market, herd behavior will magnify this shock and the price will increase or decrease more than it should be. This bubble or crash will further enhance the herd behavior and the herd behavior will again push the price further away. This is how bubbles and crashes are created. However, if the institutional investors are herding, they will stable the price instead of creating bubbles. As institutional investors are professional and relatively rational, the herd behavior among them will make the right or rational decisions widely spread. Thus, the price will be stable.

However, because of the complexity of the stock market and the difficulty of obtaining the data, we have only reviewed and analyzed the existing typical experiments and papers without collecting and verifying the data by ourselves. Besides, we do not have enough existing papers and experiments about this problem and these papers or experiments are relatively old.

\section{Conflicts of Interest}

The authors declare no conflicts of interest regarding the publication of this paper.

\section{References}

[1] Kang, W.J. (2013) Herd Behavior in Financial Markets. International Business Research, 6, 31-44. https://doi.org/10.5539/ibr.v6n6p31

[2] He, J. (2011) Analysis of the Causations of the Stock Bubbles in China. Master Dissertation, Institute of Finance and Science, The Ministry of Finance. 
[3] Li, J. (2016) The Evolutionary Game Analysis of Stock Market Herd Behavior in Information Asymmetry. Master Dissertation, Northwest Normal University, Lanzhou.

[4] Liu, M.G. and Li, G.Y. (2012) Evolutionary Game Analysis about the Cooperation Innovation of Enterprises, Colleges and Institutes. Industrial Technology \& Economy, 10, 137-143.

[5] Zhang, W.Y. (2006) Game Theory and Information Economics. Shanghai People's Publishing House, Shanghai.

[6] Xiao, T.J. (2004) Game Theory and Its Application. Shanghai Joint Publishing Press, Shanghai.

[7] Avery, C. and Zemsky, P. (1998) Multidimensional Uncertainty and Herd Behavior in Financial Markets. American Economic Review, 88, 724-748.

[8] Cipriani, M. and Guarino, A. (2005) Herd Behavior in a Laboratory Financial Market. American Economic Review, 95, 1427-1443. https://doi.org/10.1257/000282805775014443

[9] Cipriani, M. and Guarino, A. (2009) Herd Behavior in Financial Markets: An Experiment with Financial Market Professionals. Journal of the European Economic As sociation, 7, 206-233. https://doi.org/10.1162/JEEA.2009.7.1.206

[10] Shiller, R.J. (2000) Irrational Exuberance. Crown Business, New York.

[11] Lux, T. (1995) Herd Behaviour, Bubbles and Crashes. The Economic Journal, 105, 881-896. https://doi.org/10.2307/2235156

[12] Christian, H. (2007) Herding Behavior in Asset Markets. Journal of Financial Stability, 5, 35-36.

[13] Liu, X.D., Liu, C., Liu, S.C. and Lu, J.J. (2014) Does Herd Behavior Increase Stock Price Volatility. Systems Engineering-Theory \& Practice, 34, 1361-1368.

[14] Li, L. (2012) An Empirical Study of Herd Behavior and Stock Market Bubble. Master Dissertation, Nanjing University of Finance \& Economics, Nanjing. 